\title{
Reflexões ético-legais sobre os desafios ao dever médico na assistência ao paciente vulnerável social ${ }^{*}$
}

\author{
Reflexiones ético-legales sobre los retos al \\ deber médico en la asistencia al paciente \\ vulnerable social
}

\section{Ethical-legal reflections on the challenges \\ to the medical duty in the assistance of the \\ vulnerable social patient}

Fecha de recepción: 22 de febrero de 2016

Fecha de evaluación: 17 de abril de 2017

Fecha de aceptación: 2 de mayo de 2017

Disponible en línea: 22 de mayo de 2017

Camila Vasconcelos**

Volnei Garrafa***

Cómo citar:

Vasconcelos, C. y Garrafa, V. (2017). Reflexões ético-legais sobre os desafios ao dever médico na assistência ao paciente vulnerável social. Revista Latinoamericana de Bioética, 17(2), 42-50.

DOI: http://dx.doi.org/10.18359/rlbi.2782

* $\quad$ Artículo de investigación.

** Doutora em Bioética. Professora adjunta do Departamento de Medicina Preventiva e Social da Faculdade de Medicina da Universidade Federal da Bahia, Salvador, Bahia, Brasil. E-mail: camila.vasconcelos@ufba.br. ORCID: http://orcid.org/0000-0003-0847-0990.

*** Pós-Doutorado em Bioética. Professor Titular do Departamento de Saúde Coletiva na Faculdade de Ciências da Saúde da Universidade de Brasília, Brasil. E-mail: volnei@unb.br. ORCID: http://orcid.org/0000-0002-4656-2485 
A obrigação médico-assistencial de manter uma prática profissional coerente aos aspectos éticos e legais encontra desafios quando enfrenta circunstâncias aparentemente contraditórias. Assim, tanto situações como o devido respeito à autonomia dos sujeitos -especialmente aqueles vulneráveis socialmente- podem parecer confrontar-se aos aspectos legais concernentes à capacidade civil, quanto o dever de informação e esclarecimento ao paciente é capaz de ensejar dúvidas quando tratar-se de circunstância em que se deve aplicar o "direito de não saber". Neste contexto, o artigo analisa estas possíveis contradições a partir de breve interpretação lógico-dedutiva de seus conceitos na realidade latino-americana, segundo as perspectivas ético-legais. Abordagens filosóficas foucaultianas auxiliam na compreensão da entrega da informação como busca inicial pelo empoderamento do discurso dos pacientes, bem como as análises kantianas sobre a ideia do devido esclarecimento dialogam com a compreensão dos conceitos de maioridade e menoridade, em debate com os direitos de conhecer a verdade ou tê-las omitidas aos sujeitos. A Bioética de Intervenção, como teorização latino-americana em defesa dos sujeitos vulneráveis, traz conceitos que favorecem a compreensão contextual de necessária proteção dos sujeitos. O exercício da medicina na assistência tem encontrado desafios, sendo necessária uma compreensão ampliada de institutos que possam favorecer sua prática em respeito aos pacientes, não bastando a compreensão a respeito das questões legais, especialmente em contextos de desproteção e exclusão social.

Palavras-chave: autonomia, vulnerabilidade social, consentimento, direito de não saber, bioética de intervenção.

La obligación médico-asistencial de mantener una práctica profesional coherente a los aspectos éticos y legales encuentra desafíos cuando enfrenta circunstancias aparentemente contradictorias. Así, tanto situaciones como el debido respeto a la autonomía de los sujetos -especialmente aquellos vulnerables socialmente- pueden parecer confrontarse a los aspectos legales concernientes a la capacidad civil, cuanto el deber de información y aclaración al paciente es capaz de plantear dudas cuando se trata de una circunstancia en la que se debe aplicar el "derecho de no saber". En este contexto, el artículo analiza estas posibles contradicciones a partir de una breve interpretación lógico-deductiva de sus conceptos en la realidad latinoamericana, según las perspectivas ético-legales. Los enfoques filosóficos foucaultianas ayudan en la comprensión de la entrega de la información como la búsqueda inicial por el empoderamiento del discurso de los pacientes, así como los análisis kantianos sobre la idea de la debida aclaración, dialogan con la comprensión de los conceptos de mayoría y minoría, en debate con los derechos de conocer la verdad o haberlas omitido a los sujetos. La bioética de intervención, como teorización latinoamericana en defensa de los sujetos vulnerables, trae conceptos que favorecen la comprensión contextual de necesaria protección de los sujetos. El ejercicio de la medicina en la asistencia ha encontrado desafíos, siendo necesaria una comprensión ampliada de institutos que puedan favorecer su práctica en respeto a los pacientes, no bastando la comprensión acerca de las cuestiones legales, especialmente en contextos de desprotección y exclusión social.

Palabras clave: autonomía, vulnerabilidad social, consentimiento, derecho a no saber, bioética de intervención.

\section{Abstract}

The medical-assisting obligation to maintain a consistent professional practice to the ethical and legal issues finds challenges when faced with seemingly different circumstances. Thus, both situations and respectfully for the autonomy of individuals, especially those who are socially vulnerable, may appear to be confronted with legal aspects concerning civil capacity; as the duty of information and clarification to the patient is capable of raising doubts when it is a circumstance in which the "right not to know" should be applied. In this context, the article analyzes these possible contradictions based on a brief logical-deductive interpretation of its concepts in a Latin American reality, according to ethical-legal perspectives. Foucauldian philosophical approaches help in the understanding of the delivery of information as an initial search for the empowerment of patients' discourse, as well as Kantian analyzes on the idea of due clarification, dialogue with the understanding of the concepts of Majority and Minority in discussion with the rights to know the truth or to have them omitted to the subjects. The Bioethics of Intervention, as Latin American theorization in defense to vulnerable subjects, brings concepts that favor the contextual understanding of the necessary protection of the subjects. The practice of medicine in care has, in fact, encountered challenges, requiring a broader understanding of institutes that may favor their practice in respect of patients, not enough understanding about legal issues, especially in contexts of lack of protection and social exclusion.

Keywords: Autonomy, social vulnerability, consent, right to not know, bioethics of intervention. 


\section{Introdução}

A prática médica assistencial tem sido desafiada a assumir obrigações que, em uma leitura estrita, podem soar contraditórias. Dentre elas está à atenção à autonomia e vulnerabilidade do paciente no exercício do consentimento e do direito de não saber. Isto porque, ao passo em que são defendidos os direitos dos pacientes ao conhecimento a respeito de suas informações clínicas ?o direito de saber?, também tem sido enaltecido o direito que soa como diverso. É o direito de não saber, que se fundamenta em um desejo pela manutenção da ignorância a respeito de uma informação que, ao paciente, a revelação é capaz de importar em malefícios.

A base para ambos os direitos, contudo, é a mesma: o respeito à autonomia, que pode ser compreendido em sua perspectiva filosófica, e, ainda, confundido com a perspectiva jurídica, quando, neste último caso, vem a ser equivocadamente assemelhado à capacidade civil do paciente, em especial quando este for vulnerável.

Para a compreensão destes institutos, é importante compreender seus contextos teóricos, o que favorecerá, em seguida, uma possível reflexão propícia a abordar as condutas médicas como adequadas em seus contextos relacionais com pacientes cujas verdades precisarão ser ditas ou omitidas.

\section{Autonomia e vulnerabilidade social}

Compreendendo a autonomia como capacidade de autogovernar-se (Kant, 2005), de antemão deve-se separá-la da perspectiva jurídica de capacidade civil. Em seu artigo 5, o Código Civil do Brasil dispõe que a "menoridade cessa aos dezoito anos completos, quan- do a pessoa fica habilitada à prática de todos os atos da vida civil" (Código Civil do Brasil, 2002). Esta habilitação não deve, entretanto, ser confundida com plena competência decisional do paciente em um âmbito em que pouco conhece. Isto porque, mesmo cumprindo os critérios etários a partir do alcance da maioridade civil, é possível a manutenção da fragilidade decisional do paciente que persiste ignorante quanto ao saber pertinente à decisão, sobretudo em um contexto de vulnerabilidade social.

Esta vulnerabilidade, que traz consigo forte perspectiva bioética latino-americana, é discutida por Lorenzo no âmbito da ética em pesquisa como fato social significativo a ser considerado para proteção de indivíduos e comunidades em países em desenvolvimento (Lorenzo, 2007). Para esta proteção, devem ser consideradas circunstâncias que influenciam fortemente para ocorrência da situação de vulnerabilidade social e que interferem na autodeterminação dos sujeitos. Como exemplos significativos podem ser mencionados a debilidade do nível de instrução, a disparidade social e a exclusão da assistência à saúde (Garrafa e Prado, 2001). Tais circunstâncias requerem a implementação de medidas sociopolíticas com vistas a melhorar a capacidade de vigilância e regulação para a realização das investigações com respeito aos contextos sociais (Lorenzo, 2007).

Nestes termos, segundo Garrafa e Prado, a vulnerabilidade social tem seu significado voltado ao contexto de desproteção, desamparo e desfavorecimento de populações que vivem a exclusão social no que se refere aos avanços e benefícios advindos do desenvolvimento mundial (Garrafa e Prado, 2001). Esta é a perspectiva sobre vulnerabilidade que prepondera no contexto latino-americano, tal como assinala Correa, que aponta o seu concei- 
to para a ideia de dependência que impede ou ameaça de autodeterminação e a liberdade de escolha dos sujeitos acerca dos seus ideais de vida e desenvolvimento (Correa, 2011).

Somado a este contexto, especialmente na prática médica e segundo uma perspectiva foucaultiana, é clara a presença do binômio saber-poder, em que aquele que detém o conhecimento abordado por meio do discurso porta, por consequência, o poder, notadamente no meio que assim o reconhece (Foucault, 2009) Neste sentido, é possível compreenderse que apenas empodera-se aquele que detém o conhecimento; no caso do presente estudo, portanto, o profissional. O paciente, estando desempoderado pela ausência do saber, não pode ser considerado como em pleno exercício de sua autonomia, até que possa ser adequadamente informado e esclarecido com todas as informações pertinentes ao seu caso, em vocabulário que lhe seja acessível.

Concernente a estas análises, a Bioética de Intervenção, corrente de pensamento crítico desenvolvida na América Latina há aproximadamente vinte anos (Garrafa e Porto, 2003; Feitosa e Nascimento, 2015 e Rivas-Muñoz, Garrafa, Feitosa e Nascimento, 2015) e que já possui mais de 60 publicações indexadas, além de ser objeto de quase uma dezena de dissertações de mestrado e teses de doutorado (Martorell, 2015) auxilia nesta compreensão contextual de defesa dos sujeitos socialmente vulneráveis. Entre seus fundamentos teóricos, a Bioética de Intervenção trabalha com três acepções para desenvolver a reflexão com relação à situação e capacidade das pessoas socialmente fragilizadas e vulneráveis: libertação, empoderamento e emancipação (Garrafa, 2005). A ideia de libertação, desenvolvida pelo educador e filósofo brasileiro Paulo Freire, parte da percepção de existência de relações não equânimes quanto aos usos dos saberes e poderes, compreendendo haver socialmente contextos em que são encontrados sujeitos oprimidos pela exclusão social e educacional (Freire, 2015).

Nessa linha de reflexão, a ideia de empoderamento é discutida por Freire, que observa a sua potencialidade em tornar o sujeito apto a promover transformações (Shor e Freire, 1986), o que Amarthya Sen traz como "processos que permitem a liberdade de ações e decisões" (Sen, 2000, p. 31), na medida em que pensa o desenvolvimento como necessário ao alcance da liberdade (Garrafa, 2005), especialmente por meio da disponibilização social de "oportunidades reais" (Sen, 2000, p. 31). E sobre a emancipação, em diálogo novamente com a questão da capacidade civil, a Bioética de Intervenção a aborda como tomada de posição seguinte à libertação e ao empoderamento, importando em independência do sujeito (Garrafa, 2005, p. 129).

Assim, partindo também da compreensão kantiana de liberdade como autonomia da vontade (Kant, 2005), observa-se que esta apenas é exercida na medida em que o paciente se encontra livre inclusive da ignorância, que é, portanto, um elemento limitante, e que se soma as demais circunstâncias sociais que desfavorecem seu contexto de tomada de decisão. Daí a importância de um adequado processo de informação e esclarecimento, propícios ao empoderamento do sujeito, em uma conjuntura de liberdade para decidir.

\section{Consentimento e esclarecimento}

Quando não se conhece a respeito do que se está a decidir, a liberdade não se faz presente, mesmo que, formalmente, o critério civil esteja visível concedendo ao sujeito a "plena" 
capacidade. Neste sentido, ao médico é posto o dever de informar a fim de que o paciente possa exercer, livremente, a faculdade de consentir. Segundo Kfouri, a perspectiva jurídica - e a esta deve ser acrescentada a ético-profissional - é clara ao afirmar que: "O médico deve informar ao paciente diagnóstico, prognóstico, riscos e objetivos do tratamento. Haverá, também, de aconselhá-lo, informando-o dos riscos e prescrevendo o comportamento que o enfermo deverá adotar" (Kfouri, 2007, p. 33).

O direito à informação é constitucionalmente protegido no Brasil. Em seu artigo 5, inciso XIV, a Constituição da República Federativa do Brasil dispõe que "é assegurado a todos o acesso à informação e resguardado o sigilo da fonte, quando necessário ao exercício profissional" (Constituição Da República Federativa Do Brasil, 2016) Neste sentido, pode-se compreender que a falha ou ausência da obtenção do consentimento do paciente já é uma conduta que constitui dano, independentemente de outras circunstâncias a serem verificadas no decurso da prática médica no amparo à saúde. Trata-se de uma ausência de condição essencial, qual seja a de respeito à vontade da paciente, tal como comenta Fortes (1990), ao explicar que o "consentimento do paciente aos atos a serem praticados é um dos pontos essenciais do contrato médico, a declaração de vontade, que é fundamento para a existência do ato jurídico" (p. 520).

Ressalte-se, portanto, que a obtenção da concordância do paciente não pode ser reduzida à assinatura do Termo de Consentimento, visto que este apenas se trata de documento de formalização de um processo anterior, que deve ser cuidadoso em respeito à liberdade em decidir por meio da entrega do conhecimento, de forma esclarecida.
No que concerne à normatização para a prática da medicina sobre esta questão, o Código de Ética Médica brasileiro traz o dever de informar e de colher o consentimento de maneira explícita em seu capítulo sobre Direitos Humanos: "É vedado ao médico: Art. 22. Deixar de obter consentimento do paciente ou de seu representante legal após esclarecê-lo sobre o procedimento a ser realizado, salvo em caso de risco iminente de morte" (Conselho Federal de Medicina, 2010, p. 37).

Esta norma vai ao encontro da perspectiva internacional do direito à informação constante na Declaração Universal dos Direitos Humanos: "Artigo 19. Todo ser humano tem direito à liberdade de opinião e expressão; este direito inclui a liberdade de, sem interferência, ter opiniões e de procurar, receber e transmitir informações e ideias por quaisquer meios e independentemente de fronteiras" (Organização Das Nações Unidas - ONU, 2016).

A Recomendação do Conselho Federal de Medicina do Brasil, de $n^{\circ}$ 01/2016 (Conselho Federal de Medicina, 2016), também aborda especificidades do Consentimento Informado, e propõe, dentre outras condutas, que haja esclarecimento claro, com pertinência à circunstância específica, proporcionando uma possível decisão segura do paciente em autorizar a realização de procedimentos, estimulando a elaboração de termo escrito, com linguagem adequada à compreensão, em que pese não considerar ilícito ético a obtenção verbal.

Observe-se que importa, sobremaneira, que a informação seja "esclarecida". Ao responder sobre o que é o esclarecimento, Kant afirma: 'Esclarecimento' significa a saída do homem de sua menoridade, da qual o culpado é ele próprio. A menoridade é a incapacidade de fazer uso de seu entendimento sem a direção de outro indivíduo" (Kant, 2005, 
p. 155). Assim, em interessante contradição, podem então ser dispostos os termos "maioridade", colocada na ordem etária, e "menoridade", colocada na ordem do entendimento.

Em continuidade, Kant afirma: "O homem é o próprio culpado dessa menoridade se a sua causa não estiver na ausência do entendimento, mas na ausência de decisão e coragem de servir-se de si mesmo sem a direção de outrem" (Kant, 2005, p. 155). Neste sentido, partindo da reflexão kantiana, se a motivação para a dita menoridade do sujeito estiver na ausência do entendimento, este não é posto como responsável pela sua ignorância. Pode-se aqui reforçar o ponto de vista de que, não empoderado pelo conhecimento que deve a si ser entregue, mantém-se o paciente não informado, não esclarecido.

\section{Direito de não saber}

Por outro lado, pode-se apresentar também como legítimo o direito do paciente de "não saber" a respeito de informações que possam majorar a sua condição de doença. Trata-se, contudo, de um direito a ser praticado com cautela, especialmente pela responsabilidade que a sua aplicação inspira ao profissional da medicina. Em diálogo com Adimanto, Sócrates explica a possibilidade de uso da "mentira" como remédio, cujo emprego deva ser concernente ao médico:

Mas é que, realmente, deve ter-se alto apreço à verdade. Se, de fato, dissemos bem há pouco, se na realidade, a mentira é inútil aos deuses, mas útil aos homens sob a forma de remédio, é evidente que tal remédio se deve dar aos médicos, mas os particulares não devem tocar-lhe.

- É evidente - respondeu. (Platão, 2000, p. 78)
O Conselho Federal de Medicina brasileiro reforça a responsabilidade médica nesta questão, dispondo ser vedado ao médico "Deixar de informar ao paciente o diagnóstico, o prognóstico, os riscos e os objetivos do tratamento, salvo quando a comunicação direta possa lhe provocar dano, devendo, nesse caso, fizer a comunicação a seu representante legal" (Conselho Federal de Medicina, 2010, p. 49). Pode-se considerar ser esta uma "medida especial", tal como dispõe a finalização do Artigo 5 da Declaração Universal sobre Bioética e Direitos Humanos:

Autonomia e Responsabilidade Individual

- Deve ser respeitada a autonomia dos indivíduos para tomar decisões, quando possam ser responsáveis por essas decisões e respeitem a autonomia dos demais. Devem ser tomadas medidas especiais para proteger direitos e interesses dos indivíduos não capazes de exercer autonomia. (Organização das Nações Unidas para a Educação, a Ciência e a Cultura [Unesco], 2015, s. p.)

Contrariamente, ao analisar "um suposto direito de mentir por amor à humanidade" (Kant, 2005, p. 155), Kant diverge de qualquer exceção ao dever de dizer a verdade, compreendendo haver um perigo maior na mentira do que no exercício da verdade, ainda que tenha uma suposta bondade como fundamento, o perigo da injustiça. Ele afirma:

O que se deve compreender aqui não é o perigo de (acidentalmente) causar dano, mas, em termos gerais, o de cometer uma injustiça. É o que aconteceria se eu subordinasse o dever de veracidade, que é inteiramente incondicionado e constitui nas declarações a suprema condição do direito, a um dever condicionado e ainda a outras 
considerações. E embora por certa mentira não faça com essa ação injusta a ninguém, de um modo geral atento contra o princípio do direito, no que se refere a todas as declarações inevitavelmente necessárias (cometo uma injustiça formaliter, embora não materialiter), o que é ainda muito pior do que perpetrar uma injustiça contra certo indivíduo, porque tal ação nem mesmo supõe sempre um princípio para ela no sujeito. (Kant, 2005, p. 123)

Contudo, mesmo conhecendo a perspectiva kantiana de defesa à verdade irrestrita como obediência ao seu imperativo moral, é possível compreender-se que, ao exercer-se justificadamente a mentira em certas ocasiões - que não se assemelham à mera "mentira indiscriminada" - estas podem ser compreendidas universalmente, e não se estará necessariamente ferindo esta mesma lei-.

O "motivo justo", inclusive, é argumento utilizado para demais situações em que a prática médica conduz-se em prol de um benefício maior. A questão, portanto, não é simples, especialmente para os profissionais médicos, que exercerão ou não um dever correspondente ao direito do paciente, que pode relacionar-se tanto com um dever posto na esfera da verdade, quanto na da "mentira".

Assim, ao médico é entregue significativo encargo para a percepção sutil do que vem a ser a conduta adequada no caso concreto: a prescrição do remédio sob a forma de mentira nos termos socráticos, ou a entrega indubitável da verdade tendo em vista o risco de cometimento de injustiça nos termos kantianos. E a terceira hipótese apresenta-se como um não dizer justificado pelo motivo justo.

Em uma conjuntura de judicialização da medicina observa-se que tanto o "não dizer a verdade", quanto o "dizer a verdade" pode representar coragem daquele que decide por uma conduta ou outra, especialmente quando o faz em um contexto arriscado, de potencial risco de recebimento, por exemplo, de uma acusação judicial. Todos os atos, inclusive, deverão compor registros em prontuário médico, o que importa em proteção aos pacientes e profissionais, contando a história do ocorrido, que passará a ser justificado em documento que possibilite possível esclarecimento futuro da circunstância.

Certo é que, mesmo diante do receio de ser mal compreendido, não cabe ao profissional a irrestrita entrega da verdade quando o potencial dano está presente - possivelmente decorrente, mesmo sob o argumento de enaltecimento da autonomia do sujeito. Esta entrega seria uma perspectiva oportuna em que se poderia pensar em "livrarse" do encargo sob uma justificativa que cabe em um contexto liberal diverso da ideia de bem-estar social e amparo estatal nas relações humanas. Há que se considerar, portanto, esta análise da justeza do motivo como responsabilidade a ser assumida pelo profissional, como continuidade aos cuidados assistenciais de saúde para com o paciente.

\section{Considerações finais}

Considerando as análises aqui desenvolvidas, tem-se que o exercício assistencial da medicina tem encontrado desafios, sendo necessária uma compreensão ampliada de referenciais que poderão favorecer sua prática em respeito aos pacientes e às normativas ético-legais. Assim, faz-se necessária uma perspectiva ético-legal propícia, ainda, a considerar aspectos bioéticos em conformidade com o respeito à vulnerabilidade social, como a Bioética de Intervenção apregoa, em prol da busca pelo enal- 
tecimento da capacidade decisional dos pacientes em seus diferentes contextos socioculturais.

Neste sentido, não basta a compreensão relacionadas com as questões legais concernentes à capacidade civil para o respeito à capacidade de decisão dos pacientes, devendo-se analisar ainda o que vem a ser o exercício autônomo em atenção à vulnerabilidade social, especialmente no contexto latino -americano de marcante presença de desproteção e exclusão social.

É essencial a busca pela implementação e reforço da capacidade de decidir, especialmente pela entrega adequada do conhecimento, de maneira esclarecida, favorável ao empoderamento e à verdadeira libertação do paciente pela via do saber e atenta ao contexto em que o sujeito se insere. Seguidamente, nota-se a possibilidade do exercício do consentimento na medida em que for a efetiva vontade do paciente, cuja autonomia se apresenta, além dos critérios etários civis de maioridade.

Pode-se, contudo, ao contrário, assistir ao livre e necessário exercício do direito de não saber, quando a informação será resguardada do paciente e entregue ao seu representante legal, com quem as decisões serão, então, compartilhadas. Tem-se, esta, em circunstância em que a entrega da verdade é danosa, cabendo ao médico à análise do benefício ou malefício no uso da informação, e a tomada de decisão sobre a sua eventual entrega ou omissão, de maneira fundamentada em reflexões éticas e normativas ético-legais.

\section{Referências}

Brasil, Conselho Federal de Medicina (2010). "Código de ética médica: resolução. Resolução CFM 1.931, de 17 de setembro de 2009 (versão de bolso)". Brasília, Brasil.
Brasil, Conselho Federal de Medicina. (2016). "Recomendação CFM No 1/2016". Dispõe sobre o processo de obtenção de consentimento livre e esclarecido na assistência médica. Acessado em 30 de novembro de 2016, de http://portal.cfm.org.br/images/Recomendacoes/1_2016.pdf

Brasil, Presidência da República (2016). "Lei No 10.406, De 10 De Janeiro De 2002. Instituto Código Civil". Diário Oficial da União [DOU]. Acessado em 12 de maio de 2016, de http://www.planalto.gov.br/ccivil_03/leis/2002/110406.htm

Brasil, Constituição da República Federativa do Brasil de 1988 (1988). Diário Oficial da União. [DOU] de 5.10.1988. Acessado em 12 de maio de 2016, de http://www. planalto.gov.br/ccivil_03/Constituicao/ Constituicao.htm

Correa, F.J.L. (2011). Pobreza, vulnerabilidad y calidad de vida en América Latina. Retos para la bioética. Acta Bioethica, 17(1), 1929. DOI: https://doi.org/10.4067/S1726569X2011000100003

Foucault, M. (2009). A ordem do discurso. São Paulo: Edições Loyola.

Feitosa, S.F. e Nascimento WF. (2015). A bioética de intervenção no contexto do pensamento latino-americano contemporâneo. Revista Bioética, 23(2), 277-84. DOI: https://doi.org/10.1590/1983-80422015232066

Freire, P. (2015). Pedagogia do oprimido. Rio de Janeiro: Paz e Terra.

Fortes, P. A. C. (1990). Aspectos ético-jurídicos da responsabilidade civil do médico em Prática liberal. Saúde Pública, 24(6), 520. DOI: https://doi.org/10.1590/s003489101990000-600011 
Garrafa, V. (2005). Inclusão social no contexto político da Bioética. Revista Brasileira de Bioética, 1(2), 122-32.

Garrafa, V. e Prado, M. M. (2001). Mudanças na Declaração de Helsinki: fundamentalismo econômico, imperialismo ético e controle social. Cadernos de Saúde Pública, (17), 1489-1496. DOI: https://doi. org/10.1590/S0102-311X2001000600033, https://doi.org/10.1590/S0102311X2001000600020

Garrafa, V. e Porto, D. (2003). Intervention bioethics: a proposal for peripheral countries in a context of power and injustice. Bioethics, 17(5-6), 399-416. DOI: https:// doi.org/10.1111/1467-8519.00356

Kfouri Neto, M. (2007). Responsabilidade civil do médico. São Paulo: Brasil Editora.

Kant I. (2005). Fundamentação da metafísica dos costumes e outros escritos (Trad. L. Holzbach). São Paulo: Martin Claret.

Lorenzo, C. (2007). Los instrumentos normativos en ética de la investigación en seres humanos en América Latina: análisis de su potencial eficacia. En G. Keyeux, V. E. Penchaszadeh e A. Saada (Coords.), Ética de la investigación en seres humanos y políticas de salud pública (pp. 167-190). Bogotá: Universidad Nacional de Colombia, Unesco.

Martorell, L. B. (2015) Análise crítica da Bioética de Intervenção: um exercício de funda- mentação epistemológica. (Tese Doutorado). Universidade de Brasília, Brasil.

Organização das Nações Unidas [ONU]. Declaração Universal dos Direitos Humanos, adotada e proclamada pela resolução 217 A (III) da Assembleia Geral das Nações Unidas em 10 de dezembro de 1948. Acessado em: 30 de novembro de 2016, de http://unesdoc.unesco.org/images/0013/001394/139423por.pdf

Platão. (2000). A República. São Paulo: Brasil. Martin Claret.

Rivas-Muñoz, F., Garrafa ,V., Feitosa, S.F. e Nascimento, W. F. (2015). Bioética de Intervención, interculturalidad y no-colonialidad. Saúde e Sociedade, 24(supl. 1), 141-151. DOI: https://doi.org/10.1590/ S0104-12902015S01012

Shor, I. e Freire, P. (1986). Medo e ousadia: o cotidiano do professor. Rio de Janeiro: Paz e Terra.

Sem, A. (2000). Desenvolvimento como liberdade. São Paulo: Companhia das Letras.

Organização das Nações Unidas para a Educação, a Ciência e a Cultura [Unesco.] (2005).

Declaração Universal sobre Bioética e Direitos Humanos. Acessado em 20 de julho de 2015 http:/unesdoc.unesco.org/images/0014/001461/146180por.pdf 